\title{
Effect of supplementary zinc on orthodontic tooth movement in a rat model
}

\author{
Mohammad Sadegh Ahmad Akhoundi¹, Rezvaneh Ghazanfari², Shahroo Etemad-Moghadam³, Mojgan Alaeddini³, \\ Azam Khorshidian4, Shahram Rabbani5, Ahmad Reza Shamshiri6, Nafiseh Momeni ${ }^{4}$
}

DOI: http://dx.doi.org/10.1590/2177-6709.21.2.045-050.oar

Introduction: Osteoclasts and osteoblasts are responsible for regulating bone homeostasis during which the trace element zinc has been shown to exert a cumulative effect on bone mass by stimulating osteoblastic bone formation and inhibiting osteoclastic bone resorption.

Objective: The aim of the present study was to investigate the effects of zinc ( $\mathrm{Zn}$ ) on orthodontic tooth movement (OTM) in a rat model.

Material and Methods: A total of 44 male Wistar rats were divided into four groups of 11 animals each and received 0 , 1.5, 20 and $50 \mathrm{ppm} \mathrm{Zn}$ in distilled water for 60 days. In the last 21 days of the study, nickel-titanium closed coil springs were ligated between maxillary right incisors and first molars of all rats, and tooth movement was measured at the end of this period. Histological analysis of hematoxylin/eosin slides was performed to assess root resorption lacunae, osteoclast number and periodontal ligament (PDL) width.

Results: Mean OTM was calculated as 51.8, 49.1, 35.5 and $45 \mu \mathrm{m}$ in the 0, 1.5, 20 and $50 \mathrm{ppm}$ zinc-receiving groups, respectively. There were no significant differences in neither OTM nor histological parameters among the study groups $(p>0.05)$.

Conclusion: According to the results obtained in the current investigation, increase in supplementary zinc up to $50 \mathrm{ppm}$ does not affect the rate of OTM neither bone and root resorption in rats.

Keywords: Dietary supplement. Orthodontics. Tooth movement. Zinc.

${ }^{1}$ Professor, Tehran University of Medical Sciences, Dental Research Center, Orthodontic Department, Tehran, Iran.

${ }^{2}$ Postgraduate student, Tehran University of Medical Sciences, Prosthodontic Department, Tehran, Iran.

${ }^{3}$ Associate Professor, Tehran University of Medical Sciences, Dental Research Center, Dentistry Research Institute, Tehran, Iran.

${ }^{4}$ Dentist, Tehran University of Medical Sciences, Dental Research center,

Dentistry Research Institute, Tehran, Iran.

${ }^{5}$ Head of Experimental Research Laboratory, Tehran University of Medical

Sciences, Tehran Heart Center, Tehran, Iran.

${ }^{6}$ Tehran University of Medical Sciences, Research Center for Caries Prevention,

Dentistry Research Institute, Department of Community Oral Health, Tehran, Iran.
How to cite this article: Akhoundi MSA, Ghazanfari R, Etemad-Moghadam S, Alaeddini M, Khorshidian A, Rabbani S, Shamshiri AR, Momeni N. Effect of supplementary zinc on orthodontic tooth movement in a rat model. Dental Press J Orthod. 2016 Mar-Apr;21(2):45-50.

DOI: http://dx.doi.org/10.1590/2177-6709.21.2.045-050.oar

Submitted: January 13, 2015 - Revised and accepted: August 17, 2015

» The authors report no commercial, proprietary or financial interest in the products or companies described in this article.

Contact address: Momeni Nafiseh

E-mail: nafisehmomeni@yahoo.com 


\section{INTRODUCTION}

Zinc $(\mathrm{Zn})$ is an essential trace element that serves as a cofactor for more than 200 enzymes, and being a constituent of nearly all human cell types, plays a major role in a number of basic biological processes including proliferation, wound healing, immunity and osteogenesis. ${ }^{1}$ Deficiency of this fundamental mineral is a universal health issue, especially during adolescence due to the occurrence of growth spurts. This has led to the recognition of a need for improved public health programs to support individuals with $\mathrm{Zn}$ deficiency known to comprise half the world's population. ${ }^{2}$ Delayed bone maturation and impaired growth are two of the major consequences of insufficient $\mathrm{Zn}$ intake in pubescent individuals who are being treated worldwide by prescription of $\mathrm{Zn}$ supplements as part of their treatment regimen. ${ }^{3}$ In addition to the bone-related applications of this substance, different compounds, such as zinc gluconate glycine and zinc acetate, are routinely used as anti-cold agents. ${ }^{4}$

$\mathrm{Zn}$ impacts bone metabolism via augmentation of osteoblastic activity and down regulation of osteoclastic bone resorption, a fact reported by numerous investigations. $^{5-8}$ Bone remodeling is the foundation of orthodontic treatment and tooth movement relies on this phenomenon. ${ }^{9}$ Following the application of orthodontic forces, the periodontium responds by an inflammatory reaction leading to reorganization of its cellular components and a modification in its equilibrium in favor of bone remodeling, the end result of which would be tooth movement. ${ }^{10,11,12}$

Several authors have studied the effects of local and systemic medicaments, including dietary supplements on orthodontic tooth movement (OTM). ${ }^{13-16}$ A considerable number of patients seeking orthodontic treatment may be using medications due to general health problems; moreover, regarding the prevailing trend towards the increased use of dietary supplements among these individuals, having some notion of the effect of various drugs on OTM would be helpful for treatment planning and predicting the length of these treatment modalities. ${ }^{17}$ Considering the osteogenic potential of $\mathrm{Zn}$, along with its inhibiting impact on bone resorption, ${ }^{7}$ it was hypothesized that this substance might negatively regulate the rate of OTM in rats. Since $\mathrm{Zn}$ supplementation is becoming prevalent among patients, the present study was designed to investigate the effect of this micronutrient on tooth movement in rats.

\section{MATERIAL AND METHODS}

\section{Animals}

The experimental protocol of the current study was approved by the Ethics Committee of Tehran University of Medical Sciences (code: 91-01-70-17586-55909). A total of 44 male Wistar rats (200-250 g) were housed in plastic cages, maintained on a 12/12 hour light-dark cycle and randomly divided into four groups $(\mathrm{n}=11)$ with free access to standard laboratory chow. Their drinking water consisted of double distilled water with $\mathrm{Zn}$ sulfate added at concentrations of $0,1.5,20$ and $50 \mathrm{ppm}$ for use in the control group and groups 1, 2 and 3, respectively. ${ }^{18,19,20}$ All animals were weighed at the beginning of the study (day 1), on the first day of appliance placement (day 40) and immediately before sacrifice (day 60 ).

\section{Orthodontic treatment and measurement of tooth movement}

On day $40^{\text {th }}$ of the study period, each rat was anaesthetized with an intraperitoneal injection of xylazine HCL (6 mg/kg body weight) and ketamine $(50 \mathrm{mg} / \mathrm{kg}$ body weight) in order to receive orthodontic appliances. Based on the method suggested by Nilforoushan et al, ${ }^{22}$ nickeltitanium (NiTi) closed coil springs (NiTi, 3M Unitek, Monrovia, CA, Hitek, $0.006 \times 0.022$-in) were ligated between left maxillary first molars and incisors of all rats with 0.010-in stainless steel ligature wires to deliver a force of $60 \mathrm{~g}$ without further activation throughout the duration of the investigation. Labial and distal grooves cut, in approximation to the gingival margins of incisors, were used to retain the wires. The mesiolingual undercut of the first molar provided necessary retention in the posterior segment of the appliance. Two incisors were attached together by means of composite resin (Transbond XT, 3M Unitek, Monrovia, Calif) to achieve anterior anchorage and ensure mesial movement of molars. ${ }^{21}$ Moreover, composite resin covered the anterior ligatures to preserve the wires during the study period. This was followed by $1.5 \mathrm{~mm}$ reduction of mandibular incisors with a high-speed handpiece in order to prevent severance of the ligature wires. ${ }^{22,23}$ At the beginning of the study, none of the animals demonstrated any kind of space between first and second molars and all contacts were intact.

After orthodontic treatment, the standard rat chow was ground to provide a soft diet for the purpose of minimizing any discomfort and diminishing the chance of dislodgement or damage to the appliances. 
All animals were sacrificed on day $60^{\text {th }}$ of the study period by ether overdose followed by decapitation. A feeler gauge was employed to assess mesial movement of first molar by measuring the space between first and second molars before removal of the appliances, so as to prevent any possible distal relapse of the first molar. All measurements were repeated twice by the same operator blinded to the study groups, and the means were used for statistical analysis.

\section{Histological evaluation}

The maxillae were separated, fixed in 10\% formalin for five days and immersed in 5\% formic acid until adequately decalcified (an average of five days). Sequential $5-\mu \mathrm{m}$ serial sections were prepared from each paraffin block and the five sections containing the largest root area were chosen and analyzed histomorphometrically, as described previously. ${ }^{24,25}$ The final value was expressed as the mean of the selected sections. ${ }^{26}$ The mesial root was histomorphometrically evaluated on the section containing the full length of the root from the cemento-enamel junction (CEJ) to the apex, by means of a double-headed Olympus BX-41 light microscope equipped with a digital camera (DP25 Olympus) and analysis software (DP2BSW, Olympus). The number of osteoclasts, periodontal ligament (PDL) width, number of resorption lacunae and their depths and widths were analyzed by two observers, and disagreements were solved by consensus. ${ }^{27}$ The width of the PDL was determined coronally and apically on both mesial and distal aspects of the mesial root. ${ }^{27,28}$
All sections were measured twice by both observers on the double-headed microscope, and the mean of the two values was used in all consecutive calculations.

\section{Statistical analysis}

Differences among groups were analyzed by one-way ANOVA followed by Tukey post-hoc tests for multiple comparisons. Probability values $p<0.05$ were considered statistically significant.

\section{RESULTS}

There was a gradual increase in rats' weight during our investigation, and none of them died or demonstrated weight loss throughout the study period. No significant differences in mean overall weights were found among the four study groups $(p=0.25)$. All treated first molars shifted mesially into the space between molars and incisors (Table 1). The highest and lowest amounts of tooth movement were observed in the control and $20 \mathrm{ppm} \mathrm{Zn}$ groups, respectively; but there were no significant differences among groups $(p=0.18)$.

Descriptive histological data are shown in Table 2. Osteoclast numbers and resorptive lacunae widths and depths showed no significant differences among study groups (Table 2). Of the four measured locations of PDL width, significant difference was found only in the disto-apical area (Table 2) among groups. Based on multiple comparisons, PDL width was significantly higher in group 1 (1.5 ppm) compared to the control group $(p=0.02)$.

Table 1 - Molar separation over 21 days.

\begin{tabular}{ccccccccc}
\hline Group & $\mathbf{n}$ & \multicolumn{3}{c}{ Molar separation } & \multicolumn{3}{c}{$\mathbf{9 5 \%}$ CI } & \multicolumn{2}{c}{ Minimum } \\
\hline 50 ppm zinc* & 11 & 450 & 202 & 67 & 295 & 605 & 150 & 650 \\
20 ppm zinc & 11 & 355 & 149 & 45 & 254 & 455 & 150 & 600 \\
\hline 1.5 ppm zinc & 11 & 491 & 189 & 57 & 364 & 618 & 150 & 700 \\
\hline ppm zinc & 11 & 518 & 186 & 56 & 393 & 643 & 250 \\
\hline
\end{tabular}

*Zinc was added to distilled water. 
Table 2 - Descriptive histological data.

\begin{tabular}{|c|c|c|c|c|c|c|c|c|}
\hline & \multicolumn{2}{|c|}{$\begin{array}{l}\text { Osteoclasts number } \\
\text { Mean (SD) }\end{array}$} & \multicolumn{2}{|c|}{$\begin{array}{l}\text { Number of RL* } \\
\text { Mean (SD) }\end{array}$} & \multicolumn{2}{|c|}{$\begin{array}{c}\text { RL width } \\
\text { Mean (SD) }(\mu \mathrm{m})\end{array}$} & \multicolumn{2}{|c|}{$\begin{array}{c}\text { RL depth } \\
\text { Mean (SD) }(\mu \mathrm{m})\end{array}$} \\
\hline & Mesial & Distal & Mesial & Distal & Mesial & Distal & Mesial & Distal \\
\hline 50 ppm zinc & $1.5(1.9)$ & $1.2(2.2)$ & $0.8(0.7)$ & $0.8(1.2)$ & $57.7(84.0)$ & $69.1(105.8)$ & 31.4 (49.1) & $26.0(36.7)$ \\
\hline 20 ppm zinc & $1.5(1.7)$ & $1.6(1.6)$ & $0.5(0.7)$ & $0.7(0.8)$ & $60.4(66.5)$ & 70.9 (77.2) & $33.2(41.4)$ & $27.3(27.9)$ \\
\hline 1.5 ppm zinc & $0.9(1.6)$ & $1.2(1.7)$ & $0.9(1.0)$ & $0.8(0.8)$ & $88.5(98.1)$ & $41.7(41.6)$ & $24.0(30.5)$ & 28.0 (29.3) \\
\hline 0 ppm zinc & $0.3(0.6)$ & $0.0(0)$ & $1.0(1.5)$ & $1.0(1.5)$ & $45.2(74.9)$ & 75.4 (110.9) & $17.3(26.9)$ & $21.0(28.3)$ \\
\hline$p$ value & 0.14 & 0.10 & 0.58 & 0.97 & 0.67 & 0.82 & 0.75 & 0.95 \\
\hline
\end{tabular}

* $\mathrm{RL}=$ Resorption lacuna.

\section{DISCUSSION}

$\mathrm{Zn}$ supplements are prescribed for adults for numerous reasons. Among the various nutritional attributes of $\mathrm{Zn}$, inhibition of bone resorption and stimulation of bone growth and mineralization ${ }^{7}$ might directly influence OTM induced by orthodontic treatment. Several studies have investigated the effects of $\mathrm{Zn}$ on various aspects of bone quality, ${ }^{5,29}$ and its deficiency has been suggested to play a role in the development of osteoporosis. ${ }^{30}$

In the present study, we measured the amount of tooth movement in rats receiving 0 to $50 \mathrm{ppm}$ zinc sulfate, followed by application of a simple orthodontic appliance, and did not observe significant difference among groups, which was also confirmed by our histomorphometric analysis. The present result was in agreement with a study conducted by Abrisham et $\mathrm{a}^{8}$ who also did not find $\mathrm{Zn}$ to be effective in bone healing and reported no significant relationship between this substance and bone formation in rabbits. Similarly, a periodontal study in rats failed to demonstrate differences in pocket depths between animals receiving $\mathrm{Zn}$ containing diets and those deficient in this micronutrient. ${ }^{31}$ In contrast to our findings, $\mathrm{Zn}$ has been shown to prevent osteoporosis ${ }^{32}$ and induce osteogenesis. ${ }^{5}$

Previous investigations have indicated that the duration of $\mathrm{Zn}$ application may have an impact on its expected bone effects. Accordingly, any possible positive function of this micronutrient diminishes with time. ${ }^{8,33}$ This may explain the lack of difference in OTM between control and Zn-receiving rats; consequently, the $40^{\text {th }}$ day period of $\mathrm{Zn}$ administration prior to orthodontic treatment in the current investigation may have suppressed the activity of this element. For the same reason, it has been suggested that $\mathrm{Zn}$ should be prescribed at the initial stages of inflammatory reactions, ${ }^{34,35}$ which is known to play a major role in tooth movement. ${ }^{36}$ Additionally, a number of studies have pointed out that $\mathrm{Zn}$ can only perform where its deficiency exists; ${ }^{37}$ thus, pretreatment supplementation administered in the present study might have reduced any chance of $\mathrm{Zn}$ inadequacy and, therefore, eliminated its possible impact on OTM.

Despite the insignificant difference among our study groups, a decrease in OTM occurred from the first dose of Zn up to $20 \mathrm{ppm}$, but increased in Group 3 in which rats received $50 \mathrm{ppm}$. The decrease could be justified based on the proposed anti-resorptive effects of $\mathrm{Zn}$, but the reason for the increase may not be as simple to explain. Cerovic et a ${ }^{38}$ also reported similar findings regarding alkaline phosphatase activity and in vitro bone nodule formation with increasing $\mathrm{Zn}$ concentrations, suggesting "biphasic effects" for this element in addition to other possible processes including cytotoxicity at higher doses.

Our histomorphometric findings showed no significant difference in osteoclast number among groups. This supports our clinical OTM data, but may seem contradictory to a number of former investigations demonstrating a down-regulating influence of $\mathrm{Zn}$ on osteoclastic resorptive potential and differentiation. ${ }^{7,39,40}$ Nevertheless, osteoclastic number may not necessarily have a positive association with osteoclast function. ${ }^{41}$ Holloway et $\mathrm{al}^{42}$ reported inhibition of bone resorption following $\mathrm{Zn}$ treatment in 
osteoblastic/osteoclastic co-culture, but found increased osteoclastic numbers. However, the study situation (in vitro versus in vivo), detection methods and $\mathrm{Zn}$ administration in their research were different from those used in the present investigation.

The methods used in this study were selected based on previous research in this field; $;^{7,43}$ and, according to our findings, neither clinical nor histopathological changes were observed following $\mathrm{Zn}$ application in rats. Future studies using serum and/or urine analysis could help clarify the role of $\mathrm{Zn}$ in OTM and possibly confirm the conclusions of the current investigation. Additionally, further researches with immunohistochemical and molecular techniques are needed to understand the effect of $\mathrm{Zn}$ supplementation on bone remodeling during orthodontic treatment. If the present results are supported by future studies in animals and humans, the specific modifications in orthodontic treatment planning might not be necessary for patients receiving $\mathrm{Zn}$ as a dietary supplementation.

Regarding the four locations of PDL width measured in our study, significant difference was found only in the distoapical aspect among groups. The reason for this difference is not clear; further studies on various histopathologic features of OTM following $\mathrm{Zn}$ treatment are suggested to help clarify the role of this important micronutrient in orthodontic treatment.

\section{CONCLUSIONS}

According to the result obtained in the present study, systemic $\mathrm{Zn}$ supplementation up to $50 \mathrm{ppm}$ does not affect OTM, neither bone nor root resorption in rats. Extrapolation of these findings to human subjects would require extensive research using more sophisticated techniques and drug concentrations.

\section{Acknowledgments}

This study has been funded and supported by Tehran University of Medical Sciences (TUMS); Grant \# 132/872.

\section{Author contributions}

Conception or design of the study: AAMS, GR, RS; Data acquisition, analysis or interpretation: AAMS, GR, EMS, AM, KA, SAR; Writing the article: MN; Critical revision of the article: EMS, AM; Final approval of the article: MN; Overall responsibility: AAMS. 
1. Czerwinski AW, Clark ML, Serafetinides EA, Perrier C, Huber W. Safety and efficacy of zinc sulfate in geriatric patients. Clin Pharmacol Ther. 1974 Apr:15(4):436-41

2. Kawade R. Zinc status and its association with the health of adolescents: a review of studies in India. Glob Health Action. 2012;5:7353.

3. Dekker LH, Villamor E. Zinc supplementation in children is not associated with decreases in hemoglobin concentrations. J Nutr. 2010 May:140(5):1035-40

4. Taylor DM, Liyanage JA, Williams DR, Harding KG. A new approach to monitoring trace element concentrations and speciation in wounds and wound fluids. Appl Radiat Isot. 1998 May-Jun;49(5-6):677-9.

5. Yamaguchi M. Nutritional factors and bone homeostasis: synergistic effect with zinc and genistein in osteogenesis. Mol Cell Biochem. 2012 July:366(1-2):201-21

6. Igarashi A, Yamaguchi M. Increase in bone protein components with healing rat fractures: enhancement by zinc treatment. Int J Mol Med. 1999 Dec;4(6):615-20

7. Hadley KB, Newman SM, Hunt JR. Dietary zinc reduces osteoclast resorption activities and increases markers of osteoblast differentiation, matrix maturation, and mineralization in the long bones of growing rats. J Nutr Biochem. 2010 Apr:21(4):297-303.

8. Abrisham SM, Yaghmaei M, Abbas FM, Sharifi D, Abrisham SM. Effect of oral zinc therapy on osteogenesis in rabbits. J Oral Maxillofac Surg. 2010 July:68(7):1676-80

9. Meikle MC. The tissue, cellular, and molecular regulation of orthodontic tooth movement: 100 years after Carl Sandstedt. Eur J Orthod. 2006 Jun:28(3):221-40.

10. Pizzo G, Licata ME, Guiglia R, Giuliana G. Root resorption and orthodontic treatment. Review of the literature. Minerva Stomatol. 2007 JanFeb:56(1-2):31-44.

11. Brezniak N, Wasserstein A. Orthodontically induced inflammatory root resorption. Part I: The basic science aspects. Angle Orthod. 2002 Apr:72(2):175-9.

12. Storey E. The nature of tooth movement. Am J Orthod. 1973 Mar:63(3):292-314

13. Gameiro GH, Pereira-Neto JS, Magnani MB, Nouer DF. The influence of drugs and systemic factors on orthodontic tooth movement. J Clin Orthod. 2007 Feb; 41(2):73-8; quiz 71

14. Tyrovola JB, Spyropoulos MN. Effects of drugs and systemic factors on orthodontic treatment. Quintessence Int. 2001 May;32(5):365-71

15. Krishnan V, Davidovitch Z. The effect of drugs on orthodontic tooth movement. Orthod Craniofac Res. 2006:9(4):163-71.

16. Bartzela T, Türp JC, Motschall E, Maltha JC. Medication effects on the rate of orthodontic tooth movement: a systematic literature review. Am J Orthod Dentofacial Orthop. 2009 Jan:135(1):16-26.

17. Isaacson JR. Your patients are on drugs [editorial]. Angle Orthod 2000;70(2):96

18. Brzóska MM, Galazyn-Sidorczuk M, Rogalska J, Roszczenko A, Jurczuk M Majewska K, et al. Beneficial effect of zinc supplementation on biomechanical properties of femoral distal end and femoral diaphysis of male rats chronically exposed to cadmium. Chem Biol Interact. 2008 Feb 15:171(3):312-24

19. Brzóska MM, Rogalska J, Galazyn-Sidorczuk M, Jurczuk M, Roszczenko A Kulikowska-Karpińska E, et al. Effect of zinc supplementation on bone metabolism in male rats chronically exposed to cadmium. Toxicology. 2007 July 31:237(1-3):89-103.

20. Fong LY, Jiang Y, Rawahneh ML, Smalley KJ, Croce CM, Farber JL, et al. Zinc supplementation suppresses 4-nitroquinoline 1-oxide-induced rat oral carcinogenesis. Carcinogenesis. 2011 Apr;32(4):554-60.

21. Shirazi M, Khosrowshahi M, Dehpour AR. The effect of chronic renal insufficiency on orthodontic tooth movement in rats. Angle Orthod. 2001 Dec;71(6):494-8
22. Nilforoushan D, Shirazi M, Dehpour AR. The role of opioid systems on orthodontic tooth movement in cholestatic rats. Angle Orthod. 2002 Oct; $72(5): 476-80$

23. Sirisoontorn I, Hotokezaka H, Hashimoto M, Gonzales C, Luppanapornlarp S, Darendeliler MA, et al. Orthodontic tooth movement and root resorption in ovariectomized rats treated by systemic administration of zoledronic acid. Am J Orthod Dentofacial Orthop. 2012 May;141(5):563-73.

24. Hakami Z, Kitaura H, Kimura K, Ishida M, Sugisawa H, Ida H, et al. Effect of interleukin-4 on orthodontic tooth movement and associated root resorption. Eur J Orthod. 2015 Feb;37(1):87-94.

25. Taddei SR, Andrade I Jr, Queiroz-Junior CM, Garlet TP, Garlet GP, Cunha FQ, et al. Role of CCR2 in orthodontic tooth movement. Am J Orthod Dentofacial Orthop. 2012 Feb;141(2):153-60

26. Leiker BJ, Nanda RS, Currier GF, Howes RI, Sinha PK. The effects of exogenous prostaglandins on orthodontic tooth movement in rats. Am J Orthod Dentofacial Orthop. 1995 Oct;108(4):380-8.

27. Sekhavat AR, Mousavizadeh K, Pakshir HR, Aslani FS. Effect of misoprostol, a prostaglandin $\mathrm{E} 1$ analog, on orthodontic tooth movement in rats. Am J Orthod Dentofacial Orthop. 2002 Nov:122(5):542-7.

28. Tengku BS, Joseph BK, Harbrow D, Taverne AA, Symons AL. Effect of a static magnetic field on orthodontic tooth movement in the rat. Eur J Orthod. 2000 Oct;22(5):475-87.

29. Kara C, Orbak R, Dagsuyu IM, Orbak Z, Bilici N, Gumustekin K. In vivo assessment of zinc deficiency on craniofacial growth in a rat model. Eur J Dent. 2009 Jan; 3(1):10-5.

30. Eberle J, Schmidmayer S, Erben RG, Stangassinger M, Roth HP. Skeletal effects of zinc deficiency in growing rats. J Trace Elem Med Biol. 1999;13(1-2):21-6.

31. Orbak R, Kara C, Ozbek E, Tezel A, Demir T. Effects of zinc deficiency on oral and periodontal diseases in rats. J Periodontal Res. 2007;42(2):138-43.

32. Yamaguchi M. Role of nutritional zinc in the prevention of osteoporosis. Mol Cell Biochem. 2010;338(1-2):241-54

33. Yamaguchi M, Mochizuki A, Okada S. Stimulatory effect of zinc on bone growth in weanling rats. J Pharmacobiodyn. 1982;5(8):619-26.

34. Kaplan B, Gönül B, Dinçer S, Dinçer Kaya FN, Babül A. Relationships between tensile strength, ascorbic acid, hydroxyproline, and zinc levels of rabbit fullthickness incision wound healing. Surg Today. 2004;34(9):747-51.

35. Savlov ED, Strain WH, Huegin F. Radiozinc studies in experimental wound healing. J Surg Res. 1962 May:2:209-12

36. Alhashimi N, Frithiof $L$, Brudvik P, Bakhiet M. Orthodontic tooth movement and de novo synthesis of proinflammatory cytokines. Am J Orthod Dentofacial Orthop. 2001 Mar:119(3):307-12.

37. Hallböök T, Lanner E. Serum-zinc and healing of venous leg ulcers. Lancet. 1972 Oct 14:2(7781):780-2

38. Cerovic A, Miletic I, Sobajic S, Blagojevic D, Radusinovic M, El-Sohemy A. Effects of zinc on the mineralization of bone nodules from human osteoblast-like cells. Biol Trace Elem Res. 2007 Apr;116(1):61-71.

39. Yamaguchi M, Weitzmann MN. Zinc stimulates osteoblastogenesis and suppresses osteoclastogenesis by antagonizing NF-אB activation. Mol Cell Biochem. 2011 Sept:355(1-2):179-86

40. Park KH, Park B, Yoon DS, Kwon SH, Shin DM, Lee JW, et al. Zinc inhibits osteoclast differentiation by suppression of $\mathrm{Ca} 2+-$-Calcineurin-NFATc1 signaling pathway. Cell Commun Signal. 2013 Oct 2;11:74

41. Karsdal MA, Martin TJ, Bollerslev J, Christiansen C, Henriksen K. Are nonresorbing osteoclasts sources of bone anabolic activity? J Bone Miner Res. 2007 Apr:22(4):487-94.

42. Holloway WR, Collier FM, Herbst RE, Hodge JM, Nicholson GC. Osteoblastmediated effects of zinc on isolated rat osteoclasts: inhibition of bone resorption and enhancement of osteoclast number. Bone. 1996 Aug;19(2):137-42.

43. Watanabe T, Nakada H, Takahashi T, Fujita K, Tanimoto Y, Sakae T, et al. Potential for acceleration of bone formation after implant surgery by using a dietary supplement: an animal study. J Oral Rehabil. 2015 Jun:42(6):447-53. 


\section{ERRATUM}

In the article Effect of supplementary zinc on orthodontic tooth movement in a rat model, published at Dental Press J Orthod. 2016 Mar-Apr;21(2):45-50, where it is written:

Ahmad Akhoundi Mohammad Sadegh, Ghazanfari Rezvaneh, EtemadMoghadam Shahroo, Alaeddini Mojgan, Khorshidian Azam, Rabbani Shahram, Shamshiri Ahmad Reza, Momeni Nafiseh.

Should be written:

Mohammad Sadegh Ahmad Akhoundi, Rezvaneh Ghazanfari, Shahroo Etemad-Moghadam, Mojgan Alaeddini, Azam Khorshidian, Shahram Rabbani, Ahmad Reza Shamshiri, Nafiseh Momeni. 